NOTICE: this is the author's version of a work that was accepted for publication in Computational and Theoretical Chemistry. Changes resulting from the publishing process, such as peer review, editing, corrections, structural formatting, and other quality control mechanisms may not be reflected in this document. Changes may have been made to this work since it was submitted for publication. A definitive version was subsequently published in Computational and Theoretical Chemistry, Vol. 1046 (2014).

DOI: 10.1016/j.comptc.2014.07.012 


\section{Assignment of Aromaticity of the Classic Heterobenzenes by Three Aromatic Criteria}

Bo Hou ${ }^{\mathrm{a}, \mathrm{b}}$, Pinggui Yi ${ }^{\mathrm{b}, *}$, Zhaoxu Wang ${ }^{\mathrm{b}}$, Shuqun Zhang ${ }^{\mathrm{a}}$, Jinhua Zhao ${ }^{\mathrm{a}}$, Ricardo L. Mancera $^{\mathrm{c}}$, Yongxian Cheng ${ }^{\mathrm{a},{ }^{*}}$ and Zhili Zuo a,

${ }^{a}$ State Key Laboratory of Phytochemistry and Plant Resources in West China, Kunming Institute of Botany, Chinese Academy of Sciences, Kunming 650201, China;

${ }^{b}$ Key Laboratory of Theoretical Chemistry and Molecular Simulation of Ministry of Education, Hunan University of Science and Technology, Xiangtan, 411201, People s Republic of China;

'School of Biomedical Sciences, CHIRI Biosciences, Curtin University, GPO Box U1987, Perth WA 6845, Australia

Abstract: Aromaticity is a key concept in physical organic chemistry. The aromatic order of the classic heterobenzenes was reported in experiment early. However, the unambiguous criteria used to validate the aromaticity of that were controversial or inadequate in theory. In this work, the global aromaticity of the compounds has been studied using the ELF, NICS and ISE. NICS $(\max )_{z z}$ was calculated based on the maximum NICS contribution to the out-of-plane zz tensor component. Two types of bonds are observed. The correlations between NICS(max $)_{\sigma z z}$ and $\operatorname{NICS}(\max )_{\pi z z}$ with respect to aromaticity are demonstrated, specifically between $\mathrm{NICS}(\max )_{\pi z z}$ and $\mathrm{ELF}_{\pi}$ $(\mathrm{cc}=0.98)$ for $\pi$ bonds. For $\sigma$ bonds, the different electron delocalization of $\sigma$ bonds out of the plane of the ring predicted well the discrepancies between NICS(max) $)_{\text {ozz }}$ and $\mathrm{ELF}_{\sigma}$. The $\sigma$ aromatic order of the classic heterobenzenes $\left(\mathrm{C}_{5} \mathrm{H}_{5} \mathrm{~N}>\mathrm{C}_{6} \mathrm{H}_{6}>\right.$

\footnotetext{
* Corresponding author:

Prof. Dr. Zhili Zuo Tel./Fax: +86-871-65227196.

E-mail address: zuozhili@mail.kib.ac.cn
} 
$\mathrm{C}_{5} \mathrm{H}_{5} \mathrm{P}>\mathrm{C}_{5} \mathrm{H}_{5} \mathrm{As}>\mathrm{C}_{5} \mathrm{H}_{5} \mathrm{Bi}, \mathrm{C}_{5} \mathrm{H}_{5} \mathrm{Sb}$ ) was proved via the level of electronic delocalization.

Keywords: NICS; ELF; Heterobenzenes; Global Aromaticity; $\pi$ Aromaticity; $\sigma$ Aromaticity

\section{Introduction}

A variety of chemical aromaticity indices have been developed on the basis of structural criteria, the harmonic oscillator model of aromaticity (HOMA) ${ }^{[1-3]}$ and ${ }^{1} \mathrm{H}$ NMR chemical shifts ${ }^{[4]}$, among others. The aromaticity or anti-aromaticity of a chemical compound defined using these indices is usually controversial. ${ }^{[5-7]}$ To have general applicability, the well-established definition of these concepts needs to be presented in a quantitative way. ${ }^{[8-14]}$ Aromaticity scales based on energy considerations have been developed, such as the aromatic stabilization energies (ASEs), ${ }^{[15-18]}$ which aims to measure the total stabilization energy of an aromatic ring by considering ring strain, hyperconjugation, differences in types of bonds, hybridization and the stabilization present in conjugated, non-aromatic systems. Ring strain and the presence of heteroatoms complicate the evaluation of ASEs and so the "isomerization method" was developed to consider the differences between the total energies of the methyl derivative of the aromatic system and its nonaromatic exocyclic methylene isomer, resulting in isomerisation stabilization energies (ISEs, correction $=0 \mathrm{kcal} / \mathrm{mol}$, Scheme 1). ${ }^{[19]}$ Although analogues of heterobenzens have been synthesized since the mid-16th century, the correspondence between aromatic character and electrons has not been fully characterised theoretically. In 2010, the 
Ring Critical Points, the magnetic susceptibility exaltation and different NICS types were studies for hetero-benzenes of the group by Ebrahimi et al. Their observations confirmed magnetic and energetic criteria aromaticity were parallel in the present species. ${ }^{[20]}$ To further confirm the above conclusion, we also presented our investigation of the aromaticity of the classic heterobenzenes $\mathrm{C}_{5} \mathrm{H}_{5} \mathrm{X}(\mathrm{X}=\mathrm{N}, \mathrm{P}, \mathrm{As}, \mathrm{Sb}$ and $\mathrm{Bi})$ using the $\mathrm{NICS}(\max )_{\mathrm{zz}}$ and the "isomerization method"). ${ }^{[21]}$ Currently, however, the lack of correlation between $\sigma$ bonds and $\pi$ bonds was used for evaluation of aromaticity and has not been proved by other methods. We present here a solution to this problem, via analysis of the Electron Localization Function (ELF) used for studying on the inherent laws of different types of bonds, and comparison of their trend curves with the reported data.

The Electron Localization Function approach, based on properties of the electron delocalization defined by the ELF of Becke and Edgecombe, ${ }^{[22,23]}$ has been introduced to explain aromaticity. ${ }^{[24,25]}$ A separation of the ELF into $\sigma$ and $\pi$ components was shown to provide a useful scheme to discuss $\sigma$ and $\pi$ character in a molecular system. ${ }^{[22,24]}$ ELF is defined in terms of the excess of local kinetic energy density according to the Pauli exclusion principle, $T(\rho(\mathrm{r}))$, and the Thomas-Fermi kinetic energy density, $T_{\mathrm{h}}(\rho(\mathrm{r}))^{[12]}$

$$
\mathrm{ELF}=\left[1+\left(\frac{T(r)}{T_{h}(r)}\right)^{2}\right]^{-1}
$$

Both $\mathrm{ELF}_{\sigma}$ and $\mathrm{ELF}_{\pi}$ are defined as the ELF value at the relative bifurcation points that is the $(3,-1)$ critical points (CPs) of the ELF basin that only contribute from different molecular orbitals ( $\pi$ orbitals or $\sigma$ orbitals). The theoretical basis of these 
indices is that the ELF value at the bifurcation point measures the interaction between adjoining ELF domains. A large ELF value indicates that electrons have a higher level of delocalization between these domains, which is commonly recognized as a feature of aromaticity. For typical organic compounds, if the average value of the sum of $\mathrm{ELF}_{\pi}$ and $\mathrm{ELF}_{\sigma}$ is larger than 0.70 , then the molecule is globally aromatic. ${ }^{[8]}$ The dual values are defined as

$$
\operatorname{ELF}_{\pi}=\frac{\sum_{n=1}^{n_{\pi}} E L F_{\pi}}{n_{\pi}} \text { and } \quad \operatorname{LLF}_{\sigma}=\frac{\sum_{n=1}^{n_{\sigma}} E L F_{\sigma}}{n_{\sigma}}
$$

Where $n_{\pi}$ and $n_{\sigma}$ are the total numbers of $\pi$ orbital and $\sigma$ orbital CPs in a molecule, respectively. According to Natural Localized Molecular Orbitals theory, NICS $(\max )_{\pi z z}$ and $\operatorname{NICS}(\max )_{\text {ozz }}$ can be derived separately as

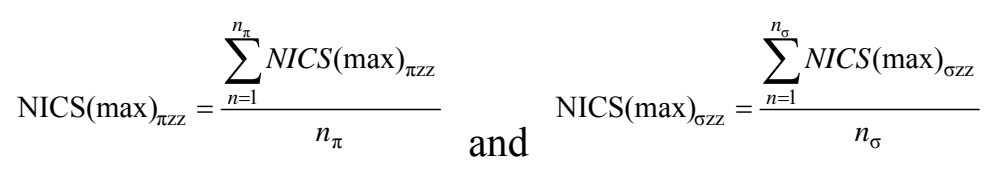

The NICS $(\max )_{\pi z z}$ represents the $z z$ tensor component of natural localized $\pi$ molecular orbitals at the value of maximum NICS of the ghost atom position on the out of the ring center. The $n_{\pi}$ is the number of $\pi$ molecular orbitals. A similar definition for NICS $(\max )_{\sigma z z}$ is defined for $\sigma$ bonds.

\section{Methods and calculations}

Fig. 1 shows the structures of the classic heterobenzenes investigated. Their geometries were fully optimized without imposing any symmetry constraints. ${ }^{[26-28]}$ The energies of the stationary points on the potential energy surface were calculated using the DFT (X3LYP) method ${ }^{[29-31]}$ in conjunction with the $6-311++G(d, p)$ and 
LANL2DZ(d, p) (Los Alamos National Laboratory 2 double $\xi$ ) basis sets. ${ }^{[32,33]}$ The previous work indicated that the above basis sets can successfully be used in analysis of NICS indices. ${ }^{[21,35]}$ Employing an effective core potential (ECP) basis set such as LANL2DZ(d,p) or def2-TZVP for the $\mathrm{X}$ atom, while using all-electron basis sets for all other non-X atoms, ${ }^{[35]}$ was necessary for computations of the $\mathrm{C}_{5} \mathrm{H}_{5} \mathrm{X}(\mathrm{X}=\mathrm{N}, \mathrm{P}, \mathrm{As}$, $\mathrm{Sb}, \mathrm{Bi}$ ) systems. The additional polarization functions have a more significant effect on the calculation of equilibrium geometries and accurate energies. At the stationary points, $\mathrm{HF} /[6-311++\mathrm{G}(\mathrm{d}, \mathrm{p})+\operatorname{LANL} 2 \mathrm{DZ}(\mathrm{d}, \mathrm{p})]$ was used in the calculation of distributions of NICS using the NBO3.1 package ${ }^{[36]}$ as implemented in Gaussian 03, and then $\mathrm{CCSD} /[6-311++\mathrm{G}(\mathrm{d}, \mathrm{p})+\mathrm{LANL} 2 \mathrm{DZ}(\mathrm{d}, \mathrm{p})]$ was used for better accuracy of the single-point calculation. Because the $\mathrm{C}_{5} \mathrm{H}_{5} \mathrm{X}$ molecules have small differences in ISEs, the different values of the electronic energies including both reactants and products (i.e. the isomerisation states) should be directly adopted by a high level of theory (CCSD method in this case). All the above calculations were carried out with the Gaussian03 package of programs. ${ }^{[37]}$ The $\sigma$ and $\pi$ orbitals were related to the $\sigma$ and $\pi$ delocalization by the corresponding critical points (CPs) values of ELF. The separate $\mathrm{ELF}_{\text {average, }} \mathrm{ELF}_{\sigma}$, and $\mathrm{ELF}_{\pi}$ were constructed with the Multiwfn2.4 software. ${ }^{[38]}$ In order to investigate the impact of basis sets, the relevant ELF were repeated at $\mathrm{HF} / 6-311++\mathrm{G}(3 \mathrm{df}, 2 \mathrm{pd})$ level for $\mathrm{C}_{6} \mathrm{H}_{6}, \mathrm{C}_{5} \mathrm{H}_{5} \mathrm{~N}$ and $\mathrm{C}_{5} \mathrm{H}_{5} \mathrm{P}$ compounds and at X3LYP/[6-311++G(d,p) + def2-TZVP $]^{[39-40]}$ level for all molecules. Cartesian coordinates, energies for all stationary points and Details of the calculation of ELF are available in the Supporting Information. 


\section{Results and Discussion}

\subsection{Global aromatic character}

Heterobenzenes have similar bond lengths, molecular orbitals, chemical stabilities and other properties. Ashe and co-workers reported many chemical properties of the classic heterobenzenes on the basis of spectral properties. They clearly demonstrated that a methine group of benzene can be replaced by isoelectronic nitrogen without disrupting its aromaticity to any significant extent. ${ }^{[26]}$ They also found that nonlocal chemical shifts were consistent with smaller ring currents from $\mathrm{N}$ to $\mathrm{Bi}$ and hence a lower aromaticity than benzene. ${ }^{[41]}$ However, the lack of a unique scale of aromaticity remains an essential limiting factor in providing a simplified assessment of aromaticity. The existence of a good linear correlation between ISEs and $\operatorname{NICS}(\max )_{z z}$ allows a separate analysis of $\pi$ bonds in terms of ELF and NICS $(\max )_{z z}$ to be readily carried out. Both Figs 2 and 3 show the existence of good linear relationships between NICS(max $)_{z z}$ and ISEs and between LLF $_{\text {average }}$ and ISEs. Global aromaticity reflects the existence of a ring current which has important magnetic properties, such that the ghost-atom positions play a critical role in determining aromaticity.

A recent review also showed that the magnitude of the NICS(max) $)_{z z}$ tensor of heterobenzenes is markedly similar to both the molecular structure and the total number of valence electrons. The ${ }^{1} \mathrm{H}$ NMR spectra of stibabenzenes and bismabenzenes showed very low field signals for the $\alpha$-protons due to the very large diamagnetic anisotropies of the $\mathrm{Sb}$ and $\mathrm{Bi}$ atoms. ${ }^{[41,42]}$ The $\alpha$-proton chemical shift of 
bismabenzene is larger $(13.25 \mathrm{ppm})$ than that of stibabenzene $(10.94 \mathrm{ppm}),{ }^{[26]}$ while the values of their corresponding $\operatorname{NICS}(\max )_{z z}$ tensors are -25.264 and -25.721 , respectively. It is important to take into account the magnetic properties of the relative heteroatom because they can influence the distribution of chemical shifts of $\alpha$-protons. ${ }^{[41]}$ We note that the best fit curve of NICS(max) $)_{z z}$ vs ISEs (Fig. 2) fits the data somewhat differently to that of $\mathrm{ELF}_{\text {average }}$ vs ISEs. Comparing with $\mathrm{ELF}_{\text {total, }}$, we can directly resort to $\mathrm{ELF}_{\text {average }}$ as an efficient aromaticity probe, and hence it is applied here. Both tensor values of $\mathrm{NICS}(\max )_{\mathrm{zz}}$ and $\mathrm{ELF}_{\text {average }}$ are effective measurements for indices of aromaticity of the molecules studied in this work.

The delocalized p-MO in $\mathrm{C}_{5} \mathrm{H}_{5} \mathrm{X}$ renders its p-aromaticity according to the famous $4 n+2$ Hückel rule. As illustrated in Fig. 4, the main NICS(max) $)_{\pi z z}$ tensor of $\pi$ orbitals including heteroatoms increase rapidly from -10.05 to -0.91 , which is in agreement with the trend of $\alpha$-proton shifts in experiment (e.g. the $\alpha$-proton shift of $\mathrm{C}_{5} \mathrm{H}_{5} \mathrm{Sb}$ is less than that of $\left.\mathrm{C}_{5} \mathrm{H}_{5} \mathrm{Bi}, 10.94 \mathrm{ppm}<13.25 \mathrm{ppm}\right) .{ }^{[41]}$ The first and the third orbitals of the heteroatoms in red color indicate the estimated magnitude of the considerably inductive effects about the $\alpha$-proton and $\beta$-proton.

\subsection{The $\pi$ and $\sigma$ aromatic character}

In order to establish adequately the determination of global aromaticity, the separation of the ELF into $\sigma\left(\mathrm{ELF}_{\sigma}\right)$ and $\pi\left(\mathrm{ELF}_{\pi}\right)$ contributions provided a useful scheme to assess the $\sigma$ and $\pi$ aromatic character in the molecules. Recently, the values of $\operatorname{ELF}_{\text {average }}(0.815), \operatorname{ELF}_{\sigma}(0.717)$ and $\operatorname{ELF}_{\pi}(0.913)$ for benzene were reported by Santo et $a l^{[42]}$ and are in excellent agreement with our results (shown in Table 1). 
When the $-\mathrm{CH}$ group in benzene is replaced by $\mathrm{N}, \mathrm{P}, \mathrm{As}, \mathrm{Sb}$ or $\mathrm{Bi}$ atoms, whose covalent radii increases in that same order (C, 73 ppm; N, 71 ppm; P, 107 ppm; As, $119 \mathrm{ppm} ; \mathrm{Sb}, 139 \mathrm{ppm}$ and $\mathrm{Bi}, 148 \mathrm{ppm}),{ }^{[43]}$ the trend in atomic size is reflected in the bond lengths from $\mathrm{N}$ to $\mathrm{Bi}(\mathrm{C}-\mathrm{C}, 1.397 \AA$; $\mathrm{C}-\mathrm{N}, 1.345 \AA$; $\mathrm{C}-\mathrm{P}, 1.773 \AA$; $\mathrm{C}-\mathrm{As}$, $1.872 \AA ; \mathrm{C}-\mathrm{Sb}, 2.059 \AA ; \mathrm{C}-\mathrm{Bi}, 2.124 \AA)^{[26,27,43]}$ With increasing $\mathrm{C}-\mathrm{X}$ bond length, the interactions of $\pi$ bonds will also decrease. Although the $\mathrm{C}-\mathrm{N}$ bond length in pyridine is shorter than the $\mathrm{C}-\mathrm{C}$ bond length in benzene, bifurcation of benzene indicated that the corresponding $\mathrm{p}_{z}-\mathrm{p}_{\mathrm{z}}$ orbitals have maximal overlap. This is clearly reflected in the values $\mathrm{ELF}_{\pi}=0.913$ (benzene) $>\mathrm{ELF}_{\pi}=0.909$ (pyridine). As can be seen in Table 1, the $\mathrm{ELF}_{\pi}$ value of benzene is larger than in the other members of this group, with the aromatic rings presenting high bifurcation values ranging from 0.913 to 0.879 . These values indicate the highly aromatic character of this molecular system (Fig. 5). The same conclusions can be drawn upon analysis of both NICS(max) $)_{z z}$ and $\mathrm{NICS}(\max )_{\pi z z}$

It is interesting to note that the values of $\mathrm{ELF}_{\sigma}$ do not always agree with the values of NICS(max) $)_{\sigma z z}$ in the linear growth model, as shown in Fig. 6. When $\mathrm{X}$ is $\mathrm{CH}, \mathrm{N}, \mathrm{P}, \mathrm{As}, \mathrm{Sb}$ and Bi the corresponding $\mathrm{ELF}_{\sigma}$ and NICS(max) $)_{\sigma z z}$ follow each other with a trend analogous to the vibration of a harmonic oscillator. ${ }^{[44]}$ For benzene and pyridine, the different metrics used resulted in greater differences. In our opinion, three possible reasons to this disagreement as following: 1) The maximum point is on the center of the ring and the $x x, y y$ and $z z$ tensor of components all contribute to the isotropic NICS(max). This is only one point of the NICS indices, so the differences 
are most likely due to an inadequate representation of all $\sigma$ bond magnetic properties. 2) The maximum point which represents $\operatorname{NICS}(\max )_{z z}$ at the ring center is far away from the $\sigma$ bonds and both the bond lengths of $\mathrm{C}-\mathrm{C}(1.397 \AA)$ and $\mathrm{C}-\mathrm{P}(1.773 \AA)$ are longer than that of $\mathrm{C}-\mathrm{N}(1.345 \AA)$, resulting in the $\sigma$ bonds becoming weaker and increasing the difference in the two metrics. 3) It is well known that the use of pseudopotentials can affect the ELF structure. The present study demonstrates that the basis sets give rise to large errors, such as the combination of $6-311++\mathrm{G}(\mathrm{d}, \mathrm{p})$ and LANL2DZ(d,p) at HF level (As evident in Fig. S2, Supporting Information). Analysis of the error line shows the components of $\mathrm{ELF}_{\sigma}$ need $\sigma$ bonds need more inner shell electrons. It indicates that the values of $\mathrm{ELF}_{\sigma}$ are strongly influenced by using inconsistent pseudopotentials level. Theoretically, the more negative values of NICS $(\max )_{\sigma z z}$ are the more positive the values of $\operatorname{ELF}_{\sigma}$. So both of $6-311++G(d, p)$ and LANL2DZ(d,p) are inappropriate or insufficient basis sets to study $\sigma$-bonds in the heterobenzens system. As the red trace showed in Fig. 6, the calculation using $6-311++\mathrm{G}(3 \mathrm{df}, 2 \mathrm{pd})$ basis set is consistent with the trend of $\mathrm{NICS}(\max )_{\sigma z z}$.

To visualize the $\sigma$ delocalization on the plane across $\mathrm{C}_{5} \mathrm{H}_{5} \mathrm{As}, \mathrm{C}_{5} \mathrm{H}_{5} \mathrm{Sb}$ and $\mathrm{C}_{5} \mathrm{H}_{5} \mathrm{Bi}$ compounds, the contour maps of $\mathrm{ELF}_{\sigma}$ were calculated, which is characterised by the white regions on each molecular plane shown in Fig. 7. The upper region represents the heteroatom and the other one is located at the center of the heterocycle. The regions indicate that the delocalization of $E_{L} F_{\sigma}$ is zero regions. For NICS $(\max )_{\sigma z z}$, the adjacent grey regions increase between the two white regions when comparing $\mathrm{C}_{5} \mathrm{H}_{5} \mathrm{Sb}$ with $\mathrm{C}_{5} \mathrm{H}_{5} \mathrm{As}$, while the other regions decrease gradually from 
$\mathrm{C}_{5} \mathrm{H}_{5} \mathrm{As}$ to $\mathrm{C}_{5} \mathrm{H}_{5} \mathrm{Sb}$ in the center of the ring, leading to an increase in the values of $\mathrm{NICS}(\max )_{\sigma z z}\left(\mathrm{C}_{5} \mathrm{H}_{5} \mathrm{Sb},-1.297>\mathrm{C}_{5} \mathrm{H}_{5} \mathrm{As},-2.170\right)$. The depth of the grey regions seems decrease on the plane of $\mathrm{C}_{5} \mathrm{H}_{5} \mathrm{Bi}$ in the center of the ring, and these regions expand to both left and right. This leads to a low value of NICS(max $)_{\text {ozz }}$ and is slightly lower than that of $\mathrm{C}_{5} \mathrm{H}_{5} \mathrm{As}\left[\mathrm{C}_{5} \mathrm{H}_{5} \mathrm{Sb}(-1.297)>\mathrm{C}_{5} \mathrm{H}_{5} \mathrm{As}(-2.170)\right.$ and $\mathrm{C}_{5} \mathrm{H}_{5} \mathrm{As}$ $\left.(-2.170)>\mathrm{C}_{5} \mathrm{H}_{5} \mathrm{Bi}(-2.185)\right]$. For $\mathrm{ELF}_{\sigma}$, the delocalization of the $\sigma$ bond regions is clearly reduced. ${ }^{[44]}$ The blue area of $\mathrm{C}_{5} \mathrm{H}_{5} \mathrm{Bi}$ is smaller than the others. $\mathrm{C}_{5} \mathrm{H}_{5} \mathrm{Sb}$ has the greatest gray area as shown by the arrow in Fig. 7, resulting in the values of ELF $\sigma$ gradually decreasing from $\mathrm{C}_{5} \mathrm{H}_{5} \mathrm{Bi}$ to $\mathrm{C}_{5} \mathrm{H}_{5} \mathrm{Sb}\left[\mathrm{C}_{5} \mathrm{H}_{5} \mathrm{As}(0.667)>\mathrm{C}_{5} \mathrm{H}_{5} \mathrm{Bi}(0.636) \cong\right.$ $\left.\mathrm{C}_{5} \mathrm{H}_{5} \mathrm{Sb}(0.625)\right]$. In short, all the values of $\mathrm{NICS}(\max )_{\sigma z z}$ were negative, which indicates that the $\sigma$ bonds of $\mathrm{C}_{5} \mathrm{H}_{5} \mathrm{X}$ molecules have $\sigma$ aromatic character. The bifurcation in $\mathrm{ELF}_{\sigma}$ also succeeds in indicating the $\sigma$ aromatic character of the classic heterobenzenes.

\section{Conclusions}

The ELF and NICS methods were used to characterize $\sigma, \pi$ and global aromaticities of the nonmetallic and semi-metallic aromatic compounds of the classic heterobenzenes. These molecules were well characterized by linear relationships between the ELF and NICS metrics. The values of the $\sigma$ bonds revealed their aromatic character, which is lower than that of the $\pi$ bonds. $\operatorname{ELF}_{\pi}$ and $\operatorname{NICS}(\max )_{\pi z z}$ were easily and efficiently applied to determine the overall aromatic character of the molecules. There was also excellent qualitative agreement with the electrons for maximum delocalization. The global aromatic order of the classic heterobenzenes 
$\left(\mathrm{C}_{6} \mathrm{H}_{6}>\mathrm{C}_{5} \mathrm{H}_{5} \mathrm{~N}>\mathrm{C}_{5} \mathrm{H}_{5} \mathrm{P}>\mathrm{C}_{5} \mathrm{H}_{5} \mathrm{As}>\mathrm{C}_{5} \mathrm{H}_{5} \mathrm{Sb}>\mathrm{C}_{5} \mathrm{H}_{5} \mathrm{Bi}\right)$ was revealed by calculation. For the $\sigma$ bonds of $\mathrm{C}-\mathrm{X}$, the traces of ELF displayed the flip-up tendency and calculations of $\mathrm{ELF}_{\sigma}$ and $\mathrm{NICS}(\max )_{\sigma z z}$ permitted overall assignment of the $\sigma$ aromatic character for all molecules.

\section{Acknowledgments}

This work was supported by the National Natural Science Foundation of China (Nos. 21172066 and 20772027) and the State Key Laboratory of Phytochemistry and Plant Resources in West China, Kunming Institute of Botany, Chinese Academy of Sciences (P2013-ZZ05). We thank Professor Lu Tian for providing the Multiwfn program and also thank National Supercomputing Center of Jinan providing.

\section{References}

[1] J. Kruszewski, T. M. Krygowski, Definition of aromaticity basing on the harmonic oscillator model, Tetrahedron Lett. 13 (1972) 3839-3842.

[2] T. M. Krygowski, M. Cyrański, Separation of the energetic and geometric contributions to the aromaticity. Part IV. A general model for the $\pi$-electron systems, Tetrahedron 52 (1996) 10255-10264.

[3] K. Srinivasu, K. R. S. Chandrakumar, S. K. Ghosh, Computational Investigation of Hydrogen Adsorption by Alkali-Metal-Doped Organic Molecules: Role of Aromaticity, Chem. Phys. Chem. 10 (2009) 427-453.

[4] Z. Chen, C. S. Wannere, C. Corminboeuf, R. Puchta, P. v. R. Schleyer, Nucleus-Independent Chemical Shifts (NICS) as an aromaticity criterion, Chem. Rev. 105 (2005) 3842-3888. 
[5] P. v. R. Schleyer, Introduction: Aromaticity, Chem. Rev. 101 (2001) 1115-1118.

[6] A. R. Katritzky, M. Karelson, S. Sild, T. M. Krygowski, K. Jug, Aromaticity as a quantitative concept. 7. Aromaticity reaffirmed as a multidimensional characteristic, J. Org. Chem. 63 (1998) 5228-5231.

[7] M. K. Cyrañski, T. M. Krygowski, A. R. Katritzky, P. v. R Schleyer, To what extent can aromaticity be defined uniquely? J. Org. Chem. 67 (2002) 1333-1338.

[8] J. C. Santos, J. Andres, A. Aizman, P. Fuentealba, An aromaticity scale based on the topological analysis of the electron localization function including $\sigma$ and $\pi$ contributions, J. Chem. Theory. Comput. 1 (2004) 83-86.

[9] P. v. R. Schleyer, K. Najafian, B. Kiran, H. Jiao, Are oxocarbon dianions aromatic? J. Org. Chem. 65 (2000) 426-431.

[10] P. v. R. Schleyer, C. Maerker, A. Dransfeld, H. Jiao, N. J. R. v. E Hommes, Nucleus-Independent Chemical Shifts: A simple and efficient aromaticity probe, J. Am. Chem. Soc. 118 (1996) 6317-6318.

[11] M. P. Johansson, J. Jusélius, D. Sundholm, Sphere currents of buckminsterfullerene. Angew. Chem. Int. Edit. 44 (2005) 1843-1846.

[12] J. C. Santos, W. Tiznado, R. Contreras, P. Fuentealba, Sigma-pi separation of the electron localization function and aromaticity, Bonding in polycyclic aromatic hydrocarbons in terms of the electron density and of electron delocalization, $J$. Chem. Phys. 120 (2004) 1670-1673.

[13] C. F. Matta, J. Hernández-Trujillo, Delocalization of electrons in molecules, J. Phys. Chem. A 107 (2003) 7496-7504. 
[14] R. Herges, D. Geuenich, Delocalization of Electrons in Molecules, J. Phys. Chem. A 105 (2001) 3214-3220.

[15] M. J. S. Dewar, H. N. Schmeising, A re-evaluation of conjugation and hyperconjugation: The effects of changes in hybridisation on carbon bonds, Tetrahedron 5 (1959) 166-178.

[16] F. De Proft, P. Geerlings, Conceptual and Computational DFT in the Study of Aromaticity, Chem. Rev. 101 (2001) 1451-1464.

[17] R. L. Disch, J. M. Schulman, Ab initio heats of formation of medium-sized hydrocarbons. 7. The [n] prismanes, J. Am. Chem. Soc. 110 (1988) 2102-2105.

[18] M. Nendel, K. N. Houk, L. M. Tolbert, E. Vogel, H. Jiao, P. v. R. Schleyer, Bond Alternation and Aromatic Character in Cyclic Polyenes: Assessment of Theoretical Methods for Computing the Structures and Energies of Bismethano [14] annulenes, J. Phys. Chem. A 102 (1998) 7191-7198.

[19] P. v. R. Schleyer, F. Pühlhofer, Recommendations for the evaluation of aromatic stabilization energies, Org. Lett. 4 (2002) 2873-2876.

[20] A. A. Ebrahimi, R. Ghiasi, C. Foroutan-Nejad, Topological characteristics of the Ring Critical Points and the aromaticity of groups IIIA to VIA hetero-benzenes, Journal of Molecular Structure: THEOCHEM, 941 (2010) 47-52.

[21] P.-G. Yi, B. Hou, Z. -X. Wang, Z.-J. Liu, X. -Y Yu, B. -Y. Xu, Study on the aromaticity of heterobenzenes $\mathrm{C}_{5} \mathrm{H}_{5} \mathrm{X}(\mathrm{X}=\mathrm{N}, \mathrm{P}, \mathrm{As}, \mathrm{Sb}, \mathrm{Bi})$ by Nucleus Independent Chemical Shifts (NICS) and Isomerization Stabilization Energies (ISE), Acta. Chim. Sinica. 71 (2013) 126-132. 
[22] B. Silvi, A. Savin, Classification of chemical bonds based on topological analysis of electron localization functions, Nature 371 (1994) 683-686.

[23] A. D. Becke, K. E. Edgecombe, A simple measure of electron localization in atomic and molecular systems, J. Chem. Phys. 92 (1990) 5397-5403.

[24] B. Silvi. How topological partitions of the electron distributions reveal delocalization, Phys. Chem. Chem. Phys. 6 (2004) 256-260.

[25] F. Fuster, A. Sevin, B. Silvi, Topological analysis of the electron localization function (ELF) applied to the electrophilic aromatic substitution, J. Phys. Chem. A 104 (2000) 852-858.

[26] A. J. Ashe, The group 5 heterobenzenes, Account. Chem. Res. 11 (1978) 153-157.

[27] B. Ma, J. -H. Lii, H. F. Schaefer, N. L. Allinger, Systematic comparison of experimental, quantum mechanical, and molecular mechanical bond lengths for organic molecules, J. Phys. Chem. 100 (1996) 8763-8769.

[28] J.-Y. Chen, M, -D. Su, Diboration of the E=E double bond by [2] metallocenophanes $(\mathrm{E}=\mathrm{N}, \mathrm{P}, \mathrm{As}, \mathrm{Sb}$, and $\mathrm{Bi}): \mathrm{A}$ theoretical study, Organometallics 29 (2010) 5812-5820.

[29] X. Xu, W. A. Goddard, Bonding properties of the water dimer: A comparative study of density functional theories, J. Phys. Chem. A 108 (2004) 2305-2313.

[30] J. P. Perdew, A. Zunger, Self-interaction correction to density-functional approximations for many-electron systems, Phys. Rev. B 23 (1981) 5048-5079.

[31] J. P. Perdew, W. Yue, Accurate and simple density functional for the electronic exchange energy: Generalized gradient, Phys. Rev. B 33 (1986) 8800-8802. 
[32] P. J. Hay, W. R. Wadt, Ab initio effective core potentials for molecular calculations. Potentials for the transition metal atoms Sc to Hg, J. Chem. Phys. 82 (1985) 270-283.

[33] P. J. Hay, W. R.Wadt, Ab initio effective core potentials for molecular calculations. Potentials for $\mathrm{K}$ to $\mathrm{Au}$ including the outermost core orbitals, $\mathrm{J}$. Chem. Phys. 82 (1985) 299-310.

[34] H. Fallah-Bagher-Shaidaei, C. S. Wannere, C. Corminboeuf, R. Puchta, P. v. R. Schleyer, Which NICS aromaticity index for planar $\pi$ rings is best? Org. Lett. 8 (2006) 863-866.

[35] C.-H. Lai, M.-D. Su, S.-Y. Chu, Theoretical study of HNXH (X = N, P, As, Sb, and Bi) isomers in the singlet and triplet States, J. Phys. Chem. A, 107 (2003) $2700-2710$.

[36] E. D. Glendening, A. E. Reed, J. E. Carpenter, Weinhold F NBO, Version 3.1. (as implemented in Gaussian 03)

[37] M. J. Frisch, G. W. Trucks, H. B. Schlegel, G. E. Scuseria, M. A. Robb, J. R. Cheeseman, J. A. Montgomery, Jr., T. Vreven, K. N. Kudin, J. C. Burant, J. M. Millam, S. S. Iyengar, J. Tomasi, V. Barone, B. Mennucci, M. Cossi, G. Scalmani, N. Rega, G. A. Petersson, H. Nakatsuji, M. Hada, M. Ehara, K. Toyota, R. Fukuda, J. Hasegawa, M. Ishida, T. Nakajima, Y. Honda, O. Kitao, H. Nakai, M. Klene, X. Li, J. E. Knox, H. P. Hratchian, J. B. Cross, V. Bakken, C. Adamo, J. Jaramillo, R. Gomperts, R. E. Stratmann, O. Yazyev, A. J. Austin, R. Cammi, C. Pomelli, J. W. Ochterski, P. Y. Ayala, K. Morokuma, G. A. Voth, P. Salvador, J. J. Dannenberg, V. 
G. Zakrzewski, S. Dapprich, A. D. Daniels, M. C. Strain, O. Farkas, D. K. Malick, A. D. Rabuck, K. Raghavachari, J. B. Foresman, J. V. Ortiz, Q. Cui, A. G. Baboul, S. Clifford, J. Cioslowski, B. B. Stefanov, G. Liu, A. Liashenko, P. Piskorz, I. Komaromi, R. L. Martin, D. J. Fox, T. Keith, M. A. Al-Laham, C. Y. Peng, A. Nanayakkara, M. Challacombe, P. M. W. Gill, B. Johnson, W. Chen, M. W. Wong, C. Gonzalez, and J. A. Pople, Gaussian 03, Revision D.01. Gaussian Inc, Wallingford, CT, 2004.

[38] T. Lu, F. W. Chen, Multiwfn: A multifunctional wavefunction analyzer, J. Comput. Chem. 33 (2012) 580-592.

[39] B. Metz, H. Stoll, M. Dolg, Small-core multiconfiguration-Dirac-Hartree-Fock-adjusted pseudopotentials for post- $d$ main group elements: Application to $\mathrm{PbH}$ and $\mathrm{PbO}$, J. Chem. Phys. 113 (2000) 2563-2569.

[40] F. Weigend, R. Ahlrichs, Balanced basis sets of split valence, triple zeta valence and quadruple zeta valence quality for $\mathrm{H}$ to $\mathrm{Rn}$ : Design and assessment of accuracy, Phys. Chem. Chem. Phys. 7 (2005) 3297-3305.

[41] A. J. Ashe, T. R. Diephouse, M. Y. El-Sheikh, Stabilization of stibabenzene and bismabenzene by 4-Alkyl Substituents, J. Am. Chem. Soc. 104 (1982) 5693-5699.

[42] J. C. Santos, P. Fuentealba, Aromaticity and electronic structure of silabenzenes. Possible existence of a new cluster $\mathrm{Si}_{6} \mathrm{Li}_{6}$, Chem. Phys. Lett. 443 (2007) 439-442.

[43] M. Winter, Webelements Periodic Table (see http://www.webelements.com/), The University of Sheffield and WebElements Ltd, England. 
[44] T. M. Krygowski, M. Cyrański, Tetrahedron, 52 (1996) 10255-10264. 


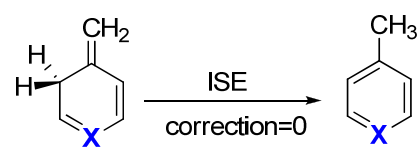

Scheme 1. The isomerisation stabilization energies were calculated by the nonaromatic isomer of the methyl derivative of the aromatic system.

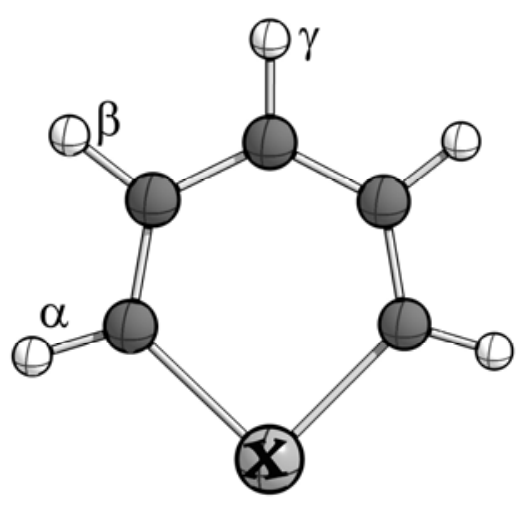

Fig. 1. The classic heterobenzenes investigated and their respective symmetry point groups. From left to right: benzene $\left(\mathrm{C}_{6} \mathrm{H}_{6}, \mathrm{D}_{6 \mathrm{~h}}\right)$, pyridine $\left(\mathrm{C}_{5} \mathrm{H}_{5} \mathrm{~N}, \mathrm{C}_{2 \mathrm{v}}\right)$, phospha-benzene $\left(\mathrm{C}_{5} \mathrm{H}_{5} \mathrm{P}, \mathrm{C}_{2 \mathrm{v}}\right)$, arsa-benzene $\left(\mathrm{C}_{5} \mathrm{H}_{5} \mathrm{As}, \mathrm{C}_{2 \mathrm{v}}\right)$, stiba-benzene $\left(\mathrm{C}_{5} \mathrm{H}_{5} \mathrm{Sb}\right.$, $\left.\mathrm{C}_{2 \mathrm{v}}\right)$ and bisma-benzene $\left(\mathrm{C}_{5} \mathrm{H}_{5} \mathrm{Bi}, \mathrm{C}_{2 \mathrm{v}}\right)$.

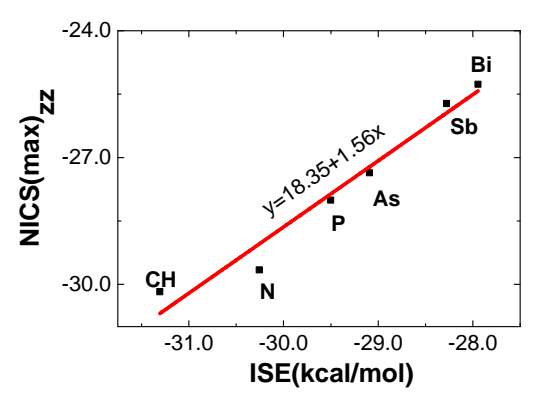

Fig. 2. Plot of the isomerization stabilization energies computed by the CCSD method vs the $z z$ tensor component of NICS(max) as computed by the HF method for the set of six-membered heterocycles $\mathrm{C}_{5} \mathrm{H}_{5} \mathrm{X}(\mathrm{X}=$ as shown, $\mathrm{cc}=0.98)$. 


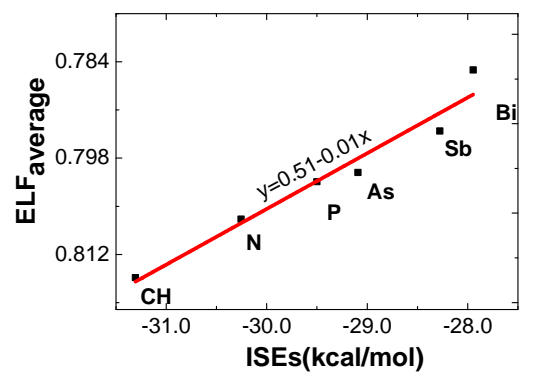

Fig. 3. Plot of the isomerization stabilization energies computed by the CCSD method vs the $\mathrm{ELF}_{\text {average }}$ as computed by the HF method for the set of six-membered heterocycles $\mathrm{C}_{5} \mathrm{H}_{5} \mathrm{X}(\mathrm{X}=$ as shown, $\mathrm{cc}=0.98)$.

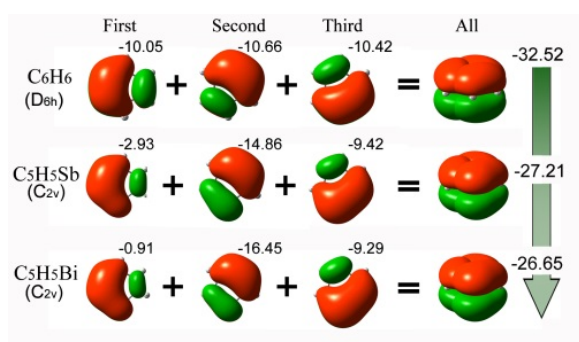

Fig. 4. The $\pi$ obtials to $\operatorname{NICS}(\max )_{\pi z z}$ tensor of benzene, stibabenzene and bimabenzene (Unit: the negative value of tensor).

\section{Table 1}

Computed values of $\mathrm{ELF}_{\text {average }}, \mathrm{ELF}_{\pi}, \mathrm{ELF}_{\sigma}, \mathrm{NICS}(\max )_{\mathrm{zz}}, \mathrm{NICS}(\max )_{\pi z z}, \mathrm{NICS}(\max )_{\sigma z z}$, and $\operatorname{ISE}^{a}$ $\left(\mathrm{kcal} \cdot \mathrm{mol}^{-1}\right)$.

\begin{tabular}{|c|c|c|c|c|c|c|c|c|}
\hline Molecules & $\mathrm{ELF}_{\text {total }}{ }^{b}$ & $\mathrm{ELF}_{\text {average }}{ }^{b}$ & $\mathrm{ELF}_{\pi}^{b}$ & $\mathrm{ELF}_{\sigma}{ }^{c}$ & $\operatorname{NICS}(\max )_{\mathrm{zz}}{ }^{b}$ & $\mathrm{NICS}(\max )_{\sigma \mathrm{zz}} b$ & $\mathrm{NICS}(\max )_{\pi \mathrm{zz}}{ }^{b}$ & ISE \\
\hline $\mathrm{C}_{6} \mathrm{H}_{6}$ & 18.398 & 0.815 & 0.913 & 0.687 & -30.173 & -2.224 & -32.522 & -31.31 \\
\hline $\mathrm{C}_{5} \mathrm{H}_{5} \mathrm{~N}$ & 18.138 & 0.807 & 0.909 & 0.702 & -29.657 & -5.527 & -31.579 & -30.26 \\
\hline $\mathrm{C}_{5} \mathrm{H}_{5} \mathrm{P}$ & 18.152 & 0.801 & 0.892 & 0.680 & -28.007 & -2.448 & -29.390 & -29.50 \\
\hline $\mathrm{C}_{5} \mathrm{H}_{5} \mathrm{As}$ & 18.145 & 0.800 & 0.888 & 0.667 & -27.361 & -2.170 & -28.706 & -29.09 \\
\hline $\mathrm{C}_{5} \mathrm{H}_{5} \mathrm{Sb}$ & 18.003 & 0.794 & 0.882 & 0.625 & -25.721 & -1.297 & -27.211 & -28.28 \\
\hline $\mathrm{C}_{5} \mathrm{H}_{5} \mathrm{Bi}$ & 17.821 & 0.788 & 0.879 & 0.636 & -25.264 & -2.185 & -26.652 & -27.95 \\
\hline
\end{tabular}

${ }^{a}$ The energies of the six-membered heterocycle compounds were calculated, with the difference of anti-syn diene mismaches using a correction $=0$ scheme being in good agreement with experimental values. ${ }^{b}$ Calculated $\operatorname{ELF}_{\text {total }}, \mathrm{ELF}_{\text {average }}, \mathrm{ELF}_{\pi}, \operatorname{NICS}(\max )_{z z}, \mathrm{NICS}(\max )_{\pi z z}$ and NICS$(\max )_{\sigma z z}$ at $\mathrm{HF} /[6-311++\mathrm{G}(\mathrm{d}, \mathrm{p})+\operatorname{LANL} 2 \mathrm{DZ}(\mathrm{d}, \mathrm{p})]$ level. ${ }^{c}$ Calculated $\mathrm{ELF}_{\sigma}$ at $\mathrm{HF} /[6-311++\mathrm{G}(\mathrm{d}, \mathrm{p})+$ LANL2DZ(d,p)] level. 


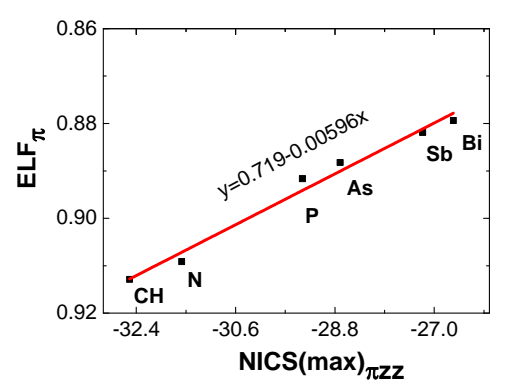

Fig. 5. Plot of the average values of $\mathrm{NICS}(\max )_{\pi z z} v s$ the average values of $\mathrm{ELF}_{\pi}$ as computed by the HF method $(\mathrm{cc}=0.98)$.

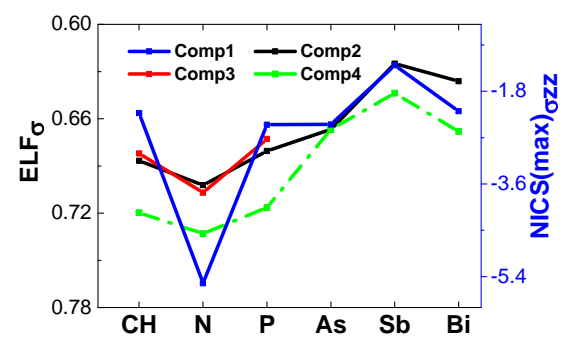

Fig. 6. HF and X3LYP methods with different basis sets are used for the study of the relationship between $\operatorname{NICS}(\max )_{\sigma z z}$ (blue line) and $\operatorname{ELF}_{\sigma}$ (other lines). [-Comp1 at $\mathrm{HF} /[6-311++\mathrm{G}(\mathrm{d}, \mathrm{p})+\mathrm{LANL} 2 \mathrm{DZ}(\mathrm{d}, \mathrm{p})]$ level; -Comp2 at HF/[6-311++G(d,p) + def2-TZVP] level; -Comp3 at HF/6-311++G(3df,2pd) level for $\mathrm{C}_{6} \mathrm{H}_{6}, \mathrm{C}_{5} \mathrm{H}_{5} \mathrm{~N}$ and $\mathrm{C}_{5} \mathrm{H}_{5} \mathrm{P} ;-\mathrm{Comp} 4$ at X3LYP/[6-311++G(d,p) + def2-TZVP] level].

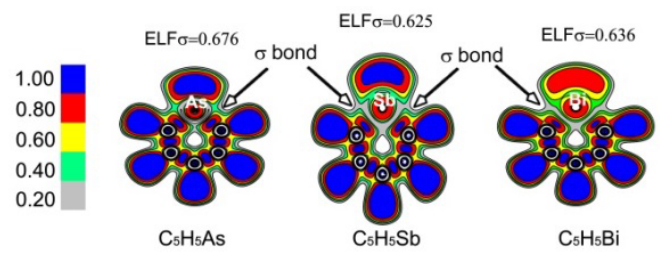

Fig. 7. $\mathrm{ELF}_{\sigma}$ bifurcation of the arsa-benzene $\left(\mathrm{C}_{5} \mathrm{H}_{5} \mathrm{As}\right)$, stiba-benzene $\left(\mathrm{C}_{5} \mathrm{H}_{5} \mathrm{Sb}\right)$ and bisma-benzene $\left(\mathrm{C}_{5} \mathrm{H}_{5} \mathrm{Bi}\right)$ in molecular planes at the $\mathrm{HF} /[6-311++\mathrm{G}(\mathrm{d}, \mathrm{p})+\operatorname{def} 2-\mathrm{TZVP}]$ level. 